\title{
A telomeric repeat sequence adjacent to a DNA double-stranded break produces an anticheckpoint
}

\author{
Rhett J. Michelson, Saul Rosenstein, and Ted Weinert ${ }^{1}$ \\ Molecular and Cellular Biology Department, University of Arizona, Tucson, Arizona 85721, USA
}

\begin{abstract}
Telomeres are complex structures that serve to protect chromosome ends. Here we provide evidence that in Saccharomyces cerevisiae telomeres may contain an anticheckpoint activity that prevents chromosome ends from signaling cell cycle arrest. We found that an internal tract of telomeric repeats inhibited DNA damage checkpoint signaling from adjacent double-strand breaks (DSBs); cell cycle arrest lasted 8-12 h from a normal DSB, whereas it lasted only 1-2 h from a DSB adjacent to a telomeric repeat. The shortened or abridged arrest was not the result of DNA repair, nor reduced amounts of single-stranded DNA, nor of adaptation. The molecular identity of this telomere repeat-associated anticheckpoint activity is unknown, though it is not dependent upon telomerase or telomere-proximal gene silencing. The anticheckpoint may inhibit the ATR yeast ortholog Mec1 because Rad9 and Rad53 became dephosphorylated and inactivated during the abridged arrest. The anticheckpoint acts regionally; it inhibited signaling from DNA breaks up to $0.6 \mathrm{~kb}$ away from the telomeric repeat but not from a DSB present on a separate chromosome. We propose that after formation of the DSB near the telomeric repeat, a mature telomere forms in 1-2 $\mathrm{h}$, and the telomere then contains proteins that inhibit checkpoint signaling from nearby DNA breaks.
\end{abstract}

[Keywords: Telomere; checkpoint; anticheckpoint; DNA damage; yeast]

Received December 27, 2004; revised version accepted August 10, 2005.

DNA damage checkpoints are surveillance mechanisms that ensure the integrity of the genetic material throughout cell cycle events (Hartwell and Weinert 1989). When cells suffer DNA damage, checkpoints cause a cell cycle delay that promotes DNA repair to maintain genome stability and cell viability (for review, see Kolodner et al. 2002; Rouse and Jackson 2002). One well studied and robust checkpoint is that present in the budding yeast Saccharomyces cerevisiae that causes a mitotic arrest in response to a single double-strand break (DSB) (Sandell and Zakian 1993). The arrest is dependent on a highly conserved phosphorylation cascade initiated by the human ATR homolog, Mec1, and relayed through the Rad53 and Chk1 kinases (checkpoints) (for review, see Zhou and Elledge 2000; Nyberg et al. 2002).

Linear eukaryotic chromosomes have specialized structures at their ends, called telomeres, that serve many functions, including the prevention of chromosome ends from behaving like DSBs. Telomeres are believed to provide a "cap" to the end of the chromosome, and if this cap is compromised the ends behave similar to a DSB by inducing DNA resection, activating recombi-

${ }^{1}$ Corresponding author.

E-MAIL tweinert@u.arizona.edu; FAX (520) 621-3709.

Article published online ahead of print. Article and publication date are at http://www.genesdev.org/cgi/doi/10.1101/gad.1293805. national repair, and allowing end-to-end fusion of chromosomes (for review, see Ferreira et al. 2004). Modulations in telomere length, either shortening or rapid expansion, can activate the DNA damage checkpoint cascade (Garvik et al. 1995; IJpma and Greider 2003; Viscardi et al. 2003); therefore, wild-type chromosome ends must have a system to recognize telomere homeostasis and prevent inappropriate cell cycle delays. Recent studies have sought to define the role of telomere-binding proteins and potential regulators, though how telomeres elude the DNA damage response is still unclear.

An emerging theme in telomere biology is that DNA damage checkpoint proteins also participate in maintaining normal telomeric integrity (for review, see D'Adda Di Fagagna et al. 2004; Maser and DePinho 2004). The checkpoint PIKKs (phosphatidyl inositol 3-kinase-like kinases), such as ATM in humans and Tell in S. cerevisiae, appear particularly important, and their inactivation results in shortened and unstable telomeres (Greenwell et al. 1995; Metcalfe et al. 1996; Hande et al. 2001). Tell and Mec1 reciprocally associate with telomeres in a cell cycle-dependent manner (Takata et al. 2004). Why checkpoint proteins are present at telomeres yet do not cause cell cycle arrest is the subject of this study.

In this report we describe the ability of an internal telomeric sequence to inhibit a DNA damage checkpoint response. We found that a DSB adjacent to a telomeric 
repeat sequence successfully activated the G2/M DNA damage checkpoint response; however, that checkpoint response was lost $1-2 \mathrm{~h}$ later $\mid<20 \%$ of the duration of a normal arrest response from a DSB). The inhibitory action of the telomeric sequence resulted in loss of Rad9 and Rad53 phosphorylation and activity. The mechanism of inhibition is unknown but it is genetically distinct from the adaptation phenomenon (Sandell and Zakian 1993; Toczyski et al. 1997; Lee et al. 1998) and does not involve telomere elongation per se or telomere-derived gene silencing. Inhibition from the new telomere extended to a second DSB present $0.6 \mathrm{~kb}$ away on the same chromosome but not to a second DSB present on a separate chromosome.

Based on the above observations we propose that the telomeric repeats act as a locus of "anticheckpoint" activity by virtue of dynamic telomere structure or by proteins that are recruited to the telomeric sequence after the break occurs. Recently a telomeric protein in mammalian cells called TRF2 was shown to inhibit the ATM protein kinase, suggesting that TRF2 could contribute to an anticheckpoint in mammals (Karlseder et al. 2004). That observation and the findings described in this report suggest that an anticheckpoint activity may be associated with normal telomeres to prevent them from being recognized as DSBs to cause cell cycle arrest.

\section{Results}

A DNA DSB near internal telomeric repeat sequences results in an abridged DNA damage checkpoint response

To investigate the checkpoint response to a DSB in proximity to telomeric sequences we used a system initially developed to examine de novo telomere synthesis in the budding yeast, $S$. cerevisiae (Diede and Gottschling $1999,2001)$. The primary strain consists of a HO endonuclease cleavage site placed directly adjacent to an 81base-pair (bp) telomeric "seed" sequence of $\mathrm{C}_{1-3} \mathrm{~A} / \mathrm{TG}_{1-3}$ repeats inserted into the $\mathrm{ADH} 4$ locus of chromosome VII (ChromVII) (Fig. 1A, TG-HO). Diede and Gottschling $(1999,2001)$ found that upon cleavage at the HO site, the telomeric seed is "healed" and gives rise to a bona fide telomere.

We used this system to ask if a DSB next to the internal $\mathrm{C}_{1-3} \mathrm{~A} / \mathrm{TG}_{1-3}$ telomeric repeats would generate a normal cell cycle arrest. Two additional strains (Fig. 1A, HO and no-HO) were created to use as controls. Cells from each of the three strains were grown in rich (YEP) medium containing sucrose and then switched to medium containing galactose to induce $\mathrm{HO}$ synthesis for $1 \mathrm{~h}$, then $\mathrm{HO}$ synthesis was turned off by the addition of glucose. We found that the presence of the telomeric repeats (TG-HO) did not inhibit cutting by the HO endonuclease (Fig. 1B; Diede and Gottschling 1999). We assayed the cell cycle arrest response of individual cells as follows. Following induction in galactose medium, we placed individual early S-phase cells (identified by their small buds) onto a YEP glucose agar plate by micromanipulation (Fig. 1C). This allowed us to follow the cell cycle fate of each cell every $30 \mathrm{~min}$; at any given time point cells that were single and large-budded we inferred to be arrested, while those that formed a new bud must have completed mitosis and entered the next cell cycle. By this assay we determined if a cell with a DSB in early $S$ phase arrests in the following mitosis. (The arrest response of cells that incur a DSB in G1 or in G2 is similar to the response of cells that have a DSB in early S phase; see below.)

In Figure 1D-G we plot the cell cycle responses of cells that had and did not have a DNA break (two separate curves). In any culture exposed to galactose, some cells incur a DNA break and some do not; at the time of plating cells we cannot of course distinguish between the two (they are all small-budded). However, after cells divide and form colonies we can easily tell which had DNA breaks and which did not. In the TG-HO strain, cells that do not have a DNA break retain the LYS2 marker and form colonies that are Lys+. In contrast, TGHO cells that have a DNA break lose the distal chromosome fragment, form a new telomere that allows them to divide, and form colonies that are Lys-(there are no essential genes in the terminal $\sim 15 \mathrm{~kb}$ of the chromosome). In the HO strains, cells that do not have a DSB survive (and are invariably Lys+), while cells that have a DSB eventually form a microcolony of $\sim 10-50$ cells that are dead. (It is important to note that a DSB in either the HO or TG-HO strains is infrequently repaired because there is no allelic sequence homology in these haploid cells to direct efficient repair.) As controls for the response of cells that did not have a DNA break, we used a "no-HO" strain (Fig. 1A). We found that any cell that did not have a DNA break had a similar response; cells resumed budding $\sim 3 \mathrm{~h}$ after plating (either the no-HO cells, or TG-HO and $\mathrm{HO}$ cells without a DSB.)

We observed a remarkable difference in the G2/M cell cycle arrest phenotypes of the HO and TG-HO strains (Fig. 1D). The kinetics of arrest for the TG-HO cells were similar to those of the HO strain for the first $1-2 \mathrm{~h}$, but after this initial arrest the TG-HO cells resumed budding while the HO cells remained arrested. (After several more hours the HO cells resumed the cell cycle by the phenomenon called "adaptation" [see below; Sandell and Zakian 1993; Toczyski et al. 1997; data not shown].) We had expected the checkpoint signaling to persist for many hours in the TG-HO strain because the DNA break centromere-distal to the new telomere should persist for many hours (and it does; see below). In sum, the results in Figure 1D suggest that in the TG-HO strain the normal DNA damage checkpoint response was activated but then was lost even though DNA damage persisted. We call this short arrest response in the TG-HO strain an "abridged arrest", and we next investigate its possible causes.

The abridged arrest requires the DNA damage checkpoint pathway

To verify that the cell cycle delay was in fact due to the DNA damage checkpoint pathway, we carried out ex- 
Figure 1. A DSB adjacent to telomeric repeat sequences results in an abridged G2/M arrest. $(A)$ Schematic representation of ChromVII in the parent strains used in this report. For the TG-HO strain (UCC5913), the ADH4 locus on the left arm of ChromVII was replaced with a 6-kb fragment containing the ADE2 gene and an $\mathrm{HO}$ endonuclease cleavage site, flanked by telomeric $\mathrm{C}_{1-3} \mathrm{~A} / \mathrm{TG}_{1-3}$ repeats $(\boldsymbol{\Delta}$ represent telomeric sequences) (Diede and Gottschling 2001). Two additional strains used as controls, HO (RMY169) and no-HO (RMY195), were constructed by replacing the HO-TG-ADE2 sequence with TRP1 or the original $A D H 4$ sequence, respectively. $(B)$ The HO site in TG-HO (UCC5913) and HO (RMY169) cells is cleaved by HO endonuclease. Cells were propagated in YEP + sucrose before receiving a 1-h induction with galactose. Genomic DNA was harvested $1 \mathrm{~h}$ later, and NdeI-cut genomic DNA was analyzed by Southern blot using a single-stranded RNA probe (RiboT3) directed to DNA 500 bp centromere-distal to the HO site. The band labeled "HO cut" is the 2.2-kb fragment generated by NdeI and HO cleavage. Two hours after the addition of galactose $(1 \mathrm{~h}$ in galactose followed by $1 \mathrm{~h}$ in glucose) we estimate that $\sim 50 \%$ of cells received a DSB by HO. $(C)$ Protocol for assaying cell cycle arrest. Exponentially dividing yeast cells grown in YEP-sucrose were treated with galactose for $1 \mathrm{~h}$ to induce $\mathrm{HO}$ and incur a DSB. The cells were then washed to remove the galactose, and small-budded (S-phase) cells were dissected into a grid on YEP-glucose agar plates. Specific cells were observed every 30 min for the formation of a new bud, indicating the exit of mitosis. In $D$, the cell cycle assay was performed with $\mathrm{HO}$, TG-HO, and no-HO strains; in $E$, mec1 (strain DSY233) was used; in F, chk1 (strain RMY171) and dun1 (strain RMY170) was used; and in G, rad52 (strain UCC5706) was used.
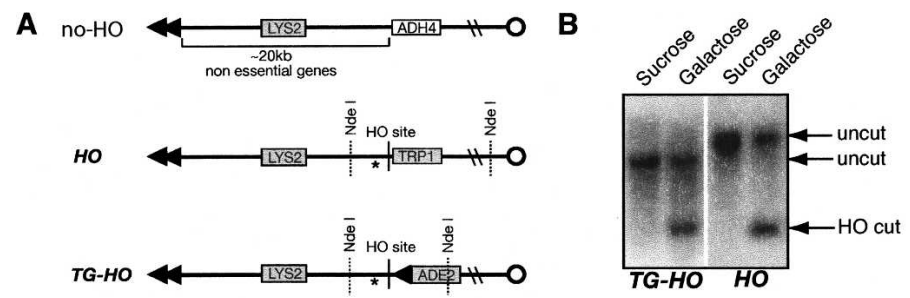

C
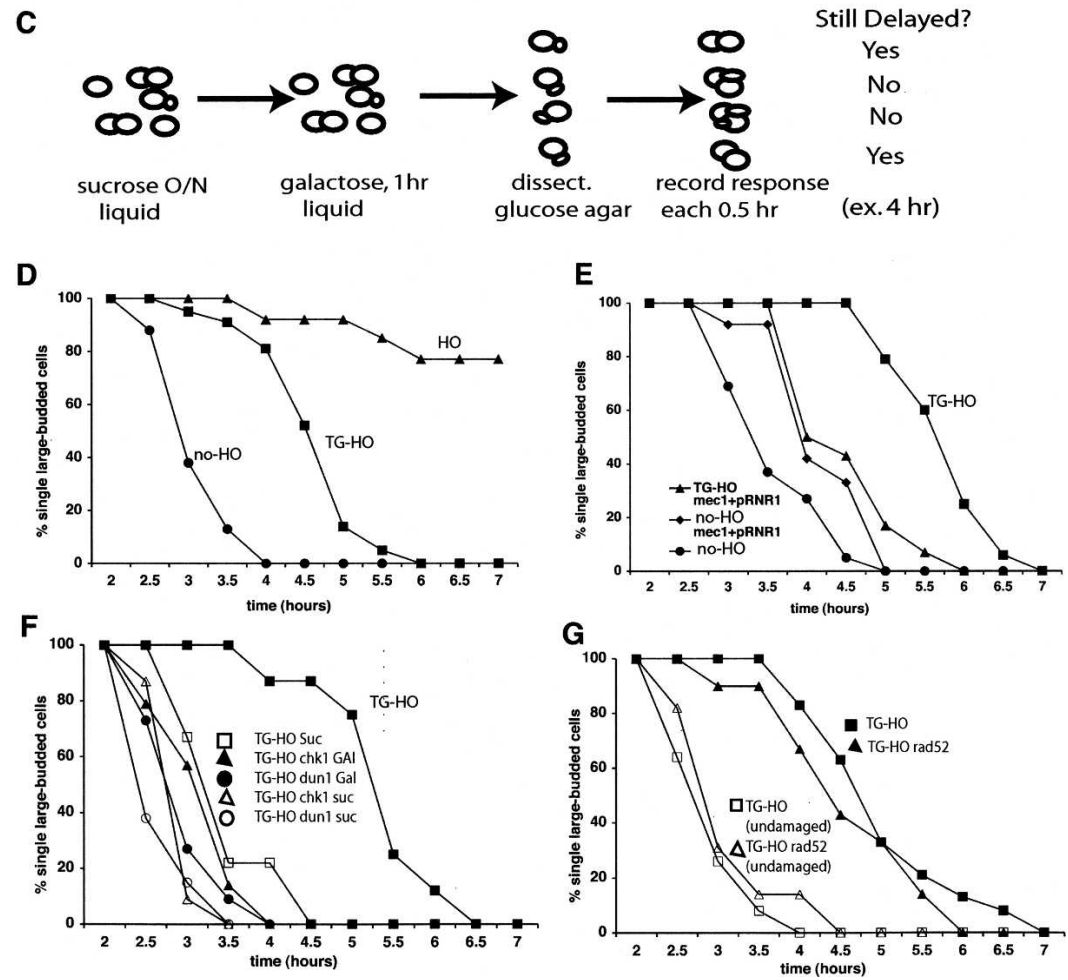

periments in strains in which DNA damage checkpoint genes had been mutated (Fig. 1E,F). Mutating the MEC1 gene abolished any delay in the TG-HO strain, as did mutations in other "upstream" checkpoint genes, RAD9, RAD17, and RAD24 (data not shown). We also tested the roles of checkpoint genes that act downstream of MEC1. MEC1 mediates the G2/M arrest by activating two parallel, downstream pathways: One pathway requires the Rad53 and Dun1 protein kinases while the other requires the Chk1 kinase and the Pds1 protein (Gardner et al. 1999; Sanchez et al. 1999). These two pathways were of particular interest because both pathways are required for a complete arrest in a cell with DNA damage; a mutation in any one of these genes results in a partial arrest that superficially resembles the abridged arrest of the TG-HO strain. However, as shown in Figure 1F, both a dun1 and a chk1 mutation completely abolished the abridged arrest; the abridged arrest is both CHK1- and DUN1-dependent. We conclude that all checkpoint genes, including the two MEC1-dependent pathways, are required for the abridged arrest of a TG-HO strain. Why a chk1 or dun1 mutation does not result in a partial arrest defect in the TG-HO strain is not clear.

\section{The abridged arrest is not the result of DNA repair}

We also considered whether the abridged arrest might be the consequence of repair of the DSB. We thought it unlikely that the abridged arrest was due to recombinational repair because the strains used in Figure 1 are haploid and therefore do not contain allelic homologous sequences that allow for efficient recombinational repair. Nevertheless, given the unusual nature of the abridged arrest kinetics we tested if genetic defects in either homologous recombination or in nonhomologous end joining affect the abridged arrest. We found that a TG-HO rad52 mutant strain that is defective in homologous recombination (Fig. 1G) and a TG-HO ku70 mutant (see below) defective in nonhomologous end joining had similar abridged arrests as the TG-HO strain. In addition, we think it unlikely that a repair event accounts for the abridged arrest in the TG-HO strain because the DNA break indeed persists for many hours (see below), and the 
LYS2 gene centromere-distal to the $\mathrm{HO}$ site was lost in cells that had undergone an abridged arrest.

The checkpoint phosphorylation cascade is inhibited by the $C_{1-3} A / T G_{1-3}$ repeat element in a temporal manner

We next sought to determine where in the checkpoint pathway the inhibition might occur. Mec1 phosphorylates Rad9 and Rad53, which act as a central convergence point between sensor proteins and effectors. Phosphorylated Rad9 and Rad53 are detectable by a shift in the electrophoretic mobility of bands on a Western blot (Sanchez et al. 1996). We examined the phosphorylation status of Rad9 and Rad53 in the TG-HO and HO strains after induction of a $\mathrm{HO}$ break (Fig. 2A,B). In $\mathrm{HO}$ cells the phosphorylation of both Rad9 and Rad53 was detectable 1-2 $\mathrm{h}$ after the galactose pulse and persisted for at least 5 h. (Since we had difficulty detecting phosphorylation of Rad53 we show MMS-treated controls; in our hands Rad53 is not as robustly phosphorylated after an HO DSB as after MMS treatment.) The TG-HO cells displayed a similar trend in the initiation of phosphorylation but didn't appear to achieve the same intensity as the HO strain, and, perhaps more importantly, the phosphorylation was less evident at $5 \mathrm{~h}$. The loss of Rad9 and Rad53 phosphorylation in the TG-HO strain correlated with the loss of arrest in Figure 1D. This suggests that Rad9 and Rad53 dephosphorylation occurred prior to attenuation of the cell cycle arrest.

A more direct assessment of checkpoint activation is the status of Rad53 enzymatic activity. To look specifically at Rad53 kinase activity in response to the $\mathrm{HO}$ break we used an in situ autophosphorylation assay (Fig. 2C; Pellicioli et al. 1999). The HO cells contained detectable enzymatic activity at $\sim 1 \mathrm{~h}$ post-galactose, which correlates well with the phosphorylation data (Fig. 2A,B). The Rad53 kinase activity not only persisted beyond $2 \mathrm{~h}$, but appeared to increase for up to $5 \mathrm{~h}$. The TG-HO cells also contained Rad53 kinase activity at $1 \mathrm{~h}$ post-galactose pulse, reached maximal levels at $3 \mathrm{~h}$, but then returned to background levels by $5 \mathrm{~h}$. This result also correlates with the phosphorylation data in Figure 2A, and indicates that Rad53 was activated in the TG-HO strain with the same kinetics as the HO strain, but the activity was lost $\sim 2 \mathrm{~h}$ later. Based on the experiments in Figure 2, we conclude that the anticheckpoint activity acts upstream of $R A D 9$ and $R A D 53$.

The abridged arrest does not require the DSB to occur in a specific cell cycle phase and is not a form of adaptation

Telomere dynamics, including lengthening by the telomerase enzyme and establishment of silencing, are influenced by cell cycle position (Dionne and Wellinger 1996; Marcand et al. 2000; Raghuraman et al. 2001). Moreover, some forms of DNA damage produce a much greater effect if the cell is allowed to traverse through $\mathrm{S}$
A
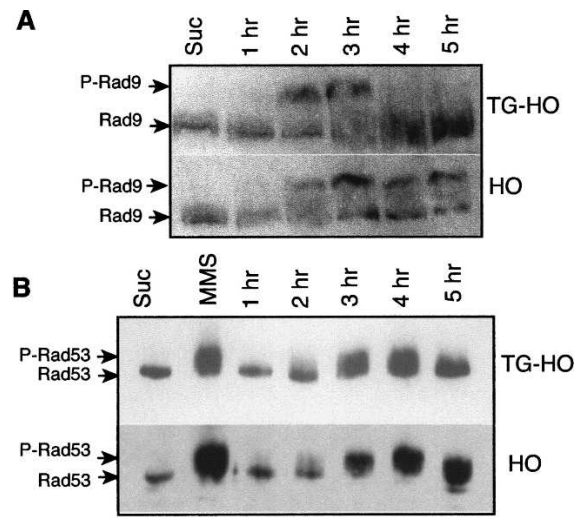

C

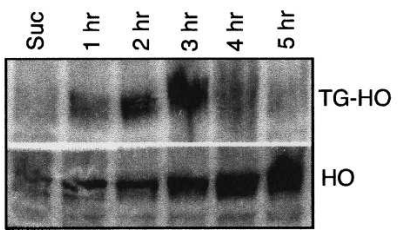

Figure 2. The anticheckpoint correlates with transient Rad53 and Rad9 phosphorylation and Rad53 kinase activity. (A) TGHO (UCC5913) and HO (RMY169) cells were induced with galactose and samples were taken every $60 \mathrm{~min}$. (Suc) Pre-galactose negative control. Approximately $50 \mu \mathrm{g}$ of total protein was loaded onto each lane of an SDS-PAGE gel, followed by Western blotting and probing with a polyclonal antibody directed toward Rad9 $(A)$ or with a monoclonal Flag antibody toward Flag-Rad53 (B). (P-Rad9) The phosphorylated form of Rad9; (P-Rad53) the phosphorylated form of Rad53. In $B$ we include MMS-treated samples $(0.02 \%, 2 \mathrm{~h})$ for comparison. $(C)$ Samples were generated as in $A$ except in place of probing with antibodies, the bound proteins were renatured and incubated with $\gamma-{ }^{32} \mathrm{P}$-ATP to detect Rad53 kinase activity.

phase (Tercero and Diffley 2001). To investigate what effects cell cycle position or cell cycle progression might have on the abridged arrest of TG-HO cells, we performed the arrest assay using cells that were either presynchronized in G1 (using $\alpha$ factor) or in G2 (using nocodozole) before $\mathrm{HO}$ induction with galactose (Fig. 3A,B, respectively). Overall, TG-HO cells still showed a shorter arrest than did HO cells when the DSB was induced in $\mathrm{G} 1$, in early $\mathrm{S}$ phase, or in the G2 phase (cf. Figs. $3 \mathrm{~A}, 1 \mathrm{C}, 3 \mathrm{~B}$, respectively). Importantly, the abridged arrest in the TG-HO strain is unaffected by progression through S phase (Fig. 3A); therefore, any explanation of the abridged arrest need not involve mechanisms of DNA replication.

We did find unexpectedly a far less robust cell cycle arrest response of $\mathrm{HO}$ cells presynchronized in G2 (compared with G1 or early S-phase cells) (e.g., Fig. 3, cf. A and B). G2 presynchronized HO cells arrested for only $\sim 5 \mathrm{~h}$ while the G1 or S presynchronized HO cells arrested for 8-12 h. We then found that this shorter arrest of G2 presynchronized $\mathrm{HO}$ cells was due to a phenomenon called "adaptation," because this shorter arrest was extended when we included a $c d c 5$ - $a d$ adaptation mutation into the HO strains (Fig. 3C; Sandell and Zakian 1993; Toczyski et al. 1997). 
Though the mechanisms underlying adaptation remain largely obscure, the shorter arrest in G2 presynchronized HO cells suggested to us that the abridged arrest in TG-HO cells might also be a form of adaptation. To test this hypothesis we introduced the $c d c 5$-ad allele into the TG-HO strain and found that the duration of the abridged arrest was unchanged (similar arrest kinetics in TG-HO $c d c 5-a d$ and TG-HO strains) (Fig. 3C). We also tested the role of $\mathrm{Ku}$ proteins that play roles in adaptation as well as in nonhomologous end joining (Lee et al. 1998). We found that the duration of the abridged arrest in TG-HO KU+ and TG-HO ku70 mutant cells were very similar (Fig. 3D). A ku80 mutation also had no effect on the abridged arrest (data not shown). We therefore conclude that the abridged arrest observed for the TG-HO strain is not a form of adaptation.

The abridged arrest is not a function of the amount of single-stranded DNA (ssDNA) or the rate of $5^{\prime}$-to-3' resection

ssDNA is believed to be a key molecular signal for cell cycle arrest (Garvik et al. 1995; Lydall and Weinert 1995; Lee et al. 1998; Zou and Elledge 2003). From a normal DSB one of the two strands on each side of the break undergoes extensive resectioning; 5'-to-3' exonucleases degrade one strand leaving the $3^{\prime}$ strand intact. In TG$\mathrm{HO}$ cells the centromere-proximal side of the break is not extensively resected because of the telomere (Diede and Gottschling 2001), while the centromere-distal side presumably is resected. Because of the unusual arrest kinetics of the TG-HO strain, we considered the possibility that the abridged arrest might be due to failure of this DSB to be resected or to lower amounts of ssDNA from the centromere-distal side of the DSB. We therefore compared the generation of ssDNA in TG-HO and $\mathrm{HO}$ cells.

To assess DNA degradation in TG-HO and HO cells, we grew cells and induced a DSB as described for cell cycle arrest assays. We then isolated genomic DNA at different times after induction of the DSB and analyzed restriction fragments by Southern hybridization to determine resection. We first used a riboprobe that was specific to the Crick strand (5'-to-3', "degraded strand") to a site $\sim 500 \mathrm{bp}$ from the HO site (Fig. 4A, asterisk). We identified the predicted $2.2-\mathrm{kb} \mathrm{NdeI} / \mathrm{HO}$ cut undegraded fragment $1 \mathrm{~h}$ after the addition of galactose (Fig. 4B). This fragment was easily detected during the first $2 \mathrm{~h}$ of $\mathrm{HO}$ induction, but by the third hour the fragment disappeared, indicating that resection had proceeded beyond the 500-bp hybridization site (Fig. 4B). (That degradation was minimal during the first $2 \mathrm{~h}$ is consistent with a previous report of little or no resection of a DSB in the first $2 \mathrm{~h}$ after HO cleavage [Frank-Vaillant and Marcand 2002].) In comparing the degradation of a DSB in HO and TG-HO cells from the data in Figure 4B, clearly degradation did occur in the TG-HO strain and to a similar
Figure 3. The abridged arrest is independent of the cell cycle stage and is not the result of early adaptation. Exponentially growing TG-HO (RMY241) and HO (RMY242) cells were either presynchronized in G1 with $\alpha$ factor before inducing $\mathrm{HO}$ endonuclease $(A)$ or synchronized in G2/M with nocodozole before inducing HO endonuclease $(B)$. The synchronization compounds were washed out and the cells were plated and assayed as shown. "Undamaged" represents cells that were treated with galactose but did not receive a DSB, and therefore did not lose the LYS2 genetic marker. (C) TG-HO (UCC5913), TG-HO cdc5-ad (RMY154), HO (RMY169), and HO cdc5-ad (RMY218) cells were arrested in G2/M with nocodozole prior to galactose induction and assayed for arrest. (D) TG-HO (RMY241), TG-HO ku70s (RMY258), and HO (RMY242) cells were synchronized with $\alpha$ factor, induced with galactose, and analyzed for G2/M arrest as in Figure 1D.
A
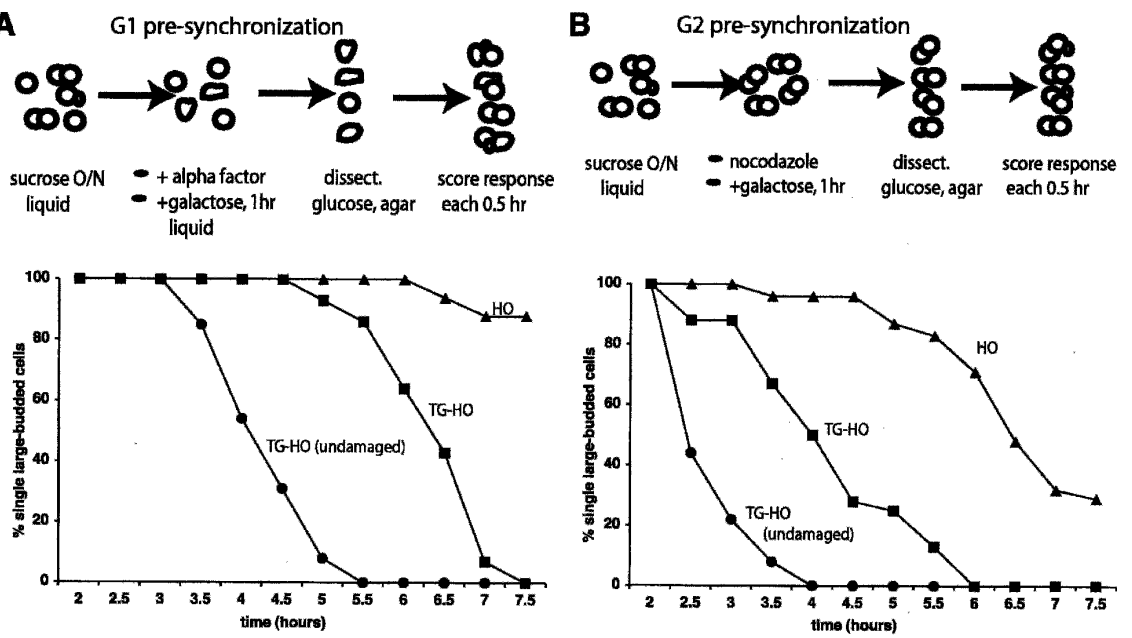

C

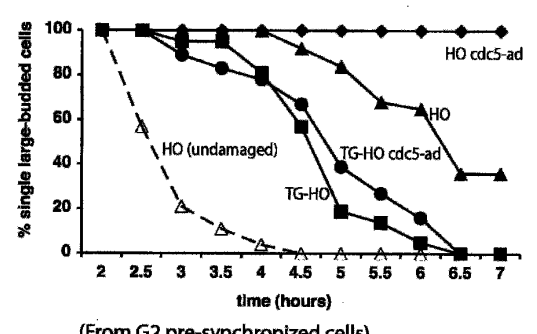

(From G2 pre-synchronized cells)

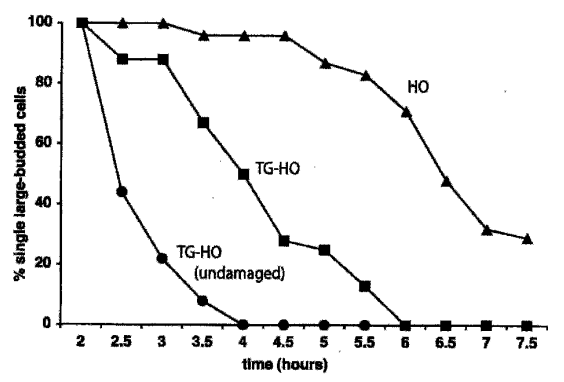

D

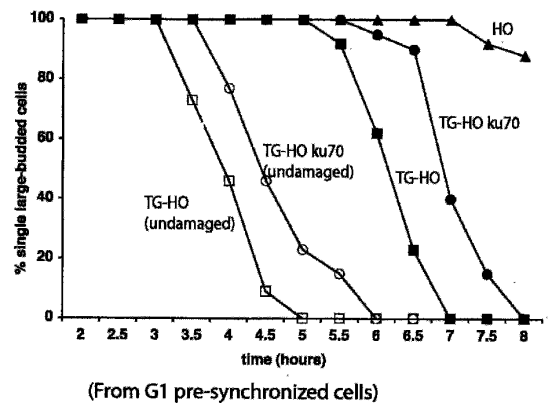


extent as in the HO strain. We also found that other aspects of DNA degradation were similar in the $\mathrm{HO}$ and TG-HO strains; the 3 '-to-5' strand (i.e., Watson strand) persisted in both strains (Fig. 4C, bottom), and degradation of the $5^{\prime}$-to- $3^{\prime}$ strand required the RAD50 gene (Fig. $4 \mathrm{C}$, top). (We also found that $\mathrm{HO}$ rad50 as well as TG$\mathrm{HO}$ rad50 mutants were completely defective in G2/M arrest; previous studies reported a less penetrant role for Rad50 [Fig. 4D,E; see Discussion].) We conclude that the amount of ssDNA and the pathway by which it is generated are similar in TG-HO and HO strains.

We performed two additional experiments to evaluate the possible relationship between ssDNA and the anticheckpoint. The first experiment was performed because we noticed that many TG-HO cells appeared to have resumed the cell cycle before a substantial amount of ssDNA had been formed; the abridged arrest lasted $1-2 \mathrm{~h}$ after $\mathrm{HO}$ induction, and the time when we detect degradation is $3 \mathrm{~h}$ after $\mathrm{HO}$ induction. This implies that many TG-HO and HO cells might have activated the checkpoint before substantial amounts of ssDNA were gener- ated. Therefore, in the TG-HO cell the checkpoint was apparently inactivated by the anticheckpoint before substantial amounts of ssDNA were generated (Figs. 1D, 4C). We therefore wished to determine if the anticheckpoint could still inhibit signaling in cells if they contained a substantial amount of ssDNA (that presumably robustly activates checkpoint signaling). To generate cells with ssDNA, we presychronized TG-HO cells in G2 (with nocodazole), induced HO synthesis by the addition of galactose, then turned off $\mathrm{HO}$ synthesis and held cells in G2 for an additional $3 \mathrm{~h}$ (by leaving them in nocodazole) to allow generation of ssDNA. We then asked whether the anticheckpoint eliminated signaling in these G2 cells by assaying cell cycle arrest after removal of nocodazole. We found that the TG-HO cells resumed cell division immediately when the nocodazole was removed (Fig. 5A). Apparently, activation of the checkpoint and its subsequent attenuation by the anticheckpoint was completed during the 3 -h period when cells were held in G2 with nocodazole. This suggests that a substantial amount of ssDNA formed from one
A

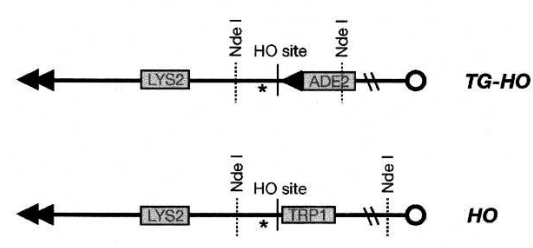

C

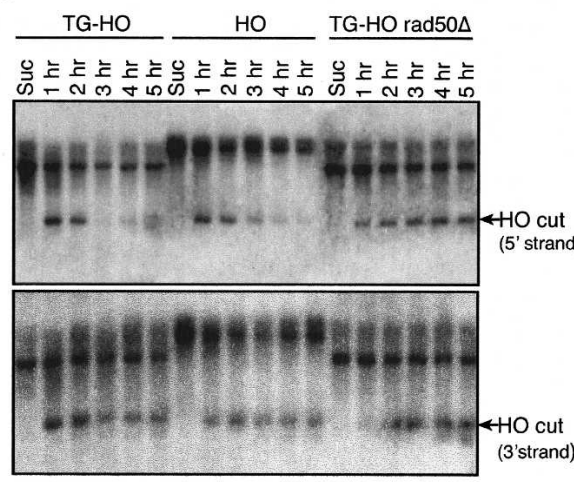

E

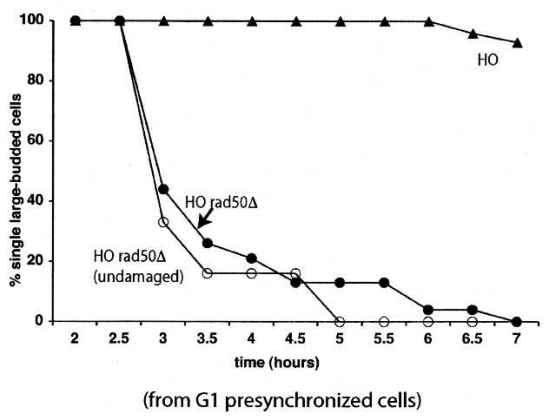

B

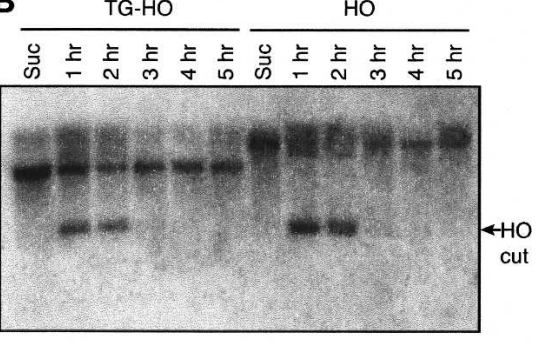

D

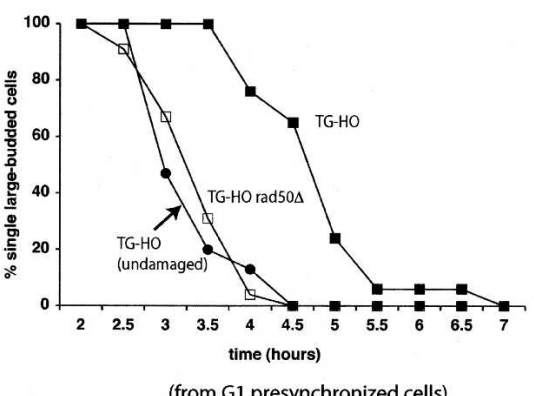

(from G1 presynchronized cells)

Figure 4. DSB resection rate is not reduced in the TG-HO strain relative to a normal HO site, and a DSB-induced arrest requires RAD50. (A) Schematics of the left arm of ChromVII in the TG-HO (UCC5913) and HO (RMY169) strains, showing the relative location of NdeI sites and the riboprobe $\left({ }^{\star}\right)$ to the HO cut site and the telomere sequences $(\mathbf{A})$. (B) TGHO (UCC5913) and HO (RMY169) cells were propagated, harvested, and assayed by Southern blot exactly as described for Figure $1 \mathrm{~B}$ over the course of $5 \mathrm{~h}$ after the galactose pulse. (C) TG-HO (UCC5913), HO (RMY169), and TG-HO rad50د (UCC8000) cells were analyzed via Southern blot as in Figure 1B, except the blot was probed with the RiboT7 probe that detects the Watson strand $\left(3^{\prime}\right.$-to-5', "nondegraded;" bottom panell instead of the Crick strand (5'-to-3', "degraded strand;" top panel). TG-HO (UCC5913) and TG-HO rad50د (UCC8000) cells $(D)$ and HO (RMY169) and HO rad50s (RMY199) $(E)$ were assayed for G2/M arrest as in Figure 1D. 
DSB in the TG-HO strain could not overcome the anticheckpoint activity.

We then performed a second experiment to evaluate the possible relationship between ssDNA, the abridged arrest, and the anticheckpoint. It has been shown that cells with two DSBs arrest for much longer (considered a "permanent arrest") than cells with one DSB (Lee et al. 1998). We considered it a formal possibility that a cell with only one resected side of a DSB may signal more poorly than a cell with two resected ends (on the two sides of one normal DSB). We therefore determined whether a cell with two resected ends from two TG-HO sites would generate an arrest as long as a cell with two resected ends from one $\mathrm{HO}$ site. To make a cell with two TG-HO sites, we inserted the TG-HO cassette into the NPR2 gene on the left arm of ChromV. We created a strain with just this ChromV site ("TG-HO ChromV"), and a second strain with the original TG-HO site on ChromVII and this second site on ChromV ("2xTG$\mathrm{HO}^{\prime \prime}$ strain) (see Materials and Methods; Fig. 5B). We found that a TG-HO cassette on ChromV alone had the same effect on cell cycle arrest as the cassette on ChromVII (Fig. 5C). (This result also indicates that the abridged arrest in the TG-HO ChromVII strain is not a phenomenon specific to ChromVII.) We then found that two DSBs next to telomeric repeats on separate chromosomes (2xTG-HO) did not produce as long as an arrest as one DSB in the HO strain (Fig. 5D). There is a longer arrest in the $2 \times \mathrm{TG}-\mathrm{HO}$ strain than in the TG-HO strain, and this result may provide insight into the nature of the anticheckpoint (see Discussion). We conclude from the results in Figures 4 and 5 that neither the amount of
ssDNA nor the number of extensively resected ends per se accounts for the phenomenon of the abridged arrest.

\section{The $C_{1-3} A / T G_{1-3}$ repeats can inhibit checkpoint signaling from another local DSB but not from a distant $D S B$}

We next determined whether the $\mathrm{C}_{1-3} \mathrm{~A} / \mathrm{TG}_{1-3}$ repeats could inhibit the checkpoint response coming from other DSBs. To investigate this we inserted an additional $\mathrm{HO}$ site on the left arm of ChromVII at $\sim 0.6 \mathrm{~kb}$ centromere-distal from the TG-HO at the ADH4 locus (Fig. 6A). Upon performing the arrest assay it was clear that the $\mathrm{C}_{1-3} \mathrm{~A} / \mathrm{TG}_{1-3}$ repeats could suppress the checkpoint arrest induced by a second DSB in close proximity (Fig. $6 \mathrm{~B}$, see legend for details). Conversely, we found that no inhibition occurred to a DSB present on another chromosome. We constructed a strain with a normal $\mathrm{HO}$ site on ChromVII and a "TG-HO" site on ChromV (Fig. 6C, $\mathrm{HO} / \mathrm{TG}-\mathrm{HO}$ ) and found that in $7.5 \mathrm{~h}$ the vast majority of the cells remained arrested (Fig. 6D). Together, these data indicate a distance restriction of the anticheckpoint from the $\mathrm{C}_{1-3} \mathrm{~A} / \mathrm{TG}_{1-3}$ repeats; inhibition occurs only at the $\mathrm{C}_{1-3} \mathrm{~A} / \mathrm{TG}_{1-3}$ telomeric repeat and in its immediate vicinity.

The inhibition by the $C_{1-3} A / T_{1-3}$ repeats is not dependent on telomerase activity or telomere-derived gene silencing

The addition of new sequence by telomerase onto the de novo telomere becomes detectable at $\sim 2 \mathrm{~h}$ and reaches
Figure 5. Enhanced ssDNA production does not prevent the anticheckpoint, and two $\mathrm{HO}$ cuts adjacent to $\mathrm{C}_{1-3} \mathrm{~A} / \mathrm{TG}_{1-3}$ repeats do not produce a permanent arrest phenotype. (A) TG-HO (UCC5913) cells were synchronized in G2/M with nocodozole. Half the culture was induced with galactose, the other was maintained in sucrose. After $1 \mathrm{~h}$ the cells were washed to remove the galactose, but nocodozole was replaced, and the cells were allowed to incubate for another $2 \mathrm{~h}$ at $30^{\circ} \mathrm{C}$ in YEP-glucose before plating and assaying for arrest as in Figure 1C. (B) Schematic representations of ChromV and/or ChromVII of the TG-HO ChromV (RMY231) and 2xTG-HO (RMY238) strains. (A) Telomeric sequences, (A) ADE2, (H) HIS3, (L) LYS2, and (T) TRP1. Using PCR, the TG-HO-ADE2 cassette from the TG-HO strain (UCC5913) was inserted into the NPR2 locus of ChromV in RMY195 to create TG-HO ChromV (RMY231). 2xTG-HO (RMY238) contains two HO cut sites on separate chromosomes flanked by $\mathrm{C}_{1-3} \mathrm{~A} /$ $\mathrm{TG}_{1-3}$ repeats. (C) TG-HO (UCC5913) and TG-HO ChromV (RMY231) strains were assayed for arrest as in Figure 1D. (D) TG-HO (UCC5913), HO (RMY169), and 2XTG-HO (RMY232) were synchronized in $\alpha$ factor prior to induction with galactose and subsequently assayed for arrest as in Figure 1D. "Undamaged" represents cells that were treated with galactose but did not receive a DSB, and therefore did not lose the LYS2 and/or URA3 genetic markers.
A

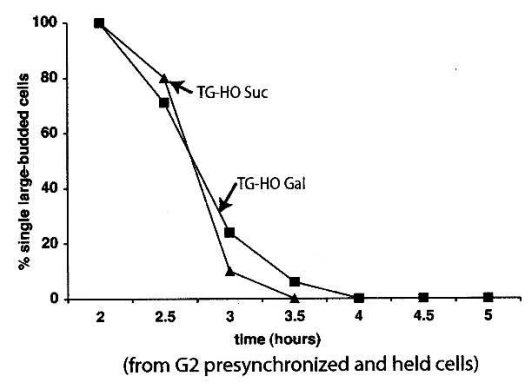

C

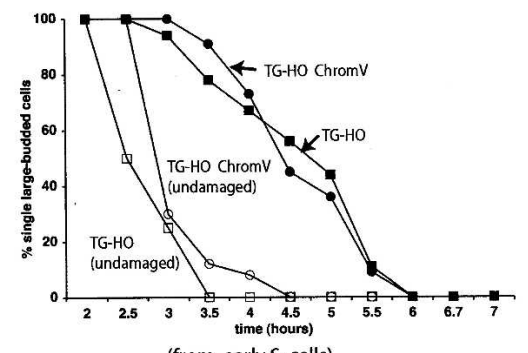

(from early $\mathrm{S}$ cells)
B
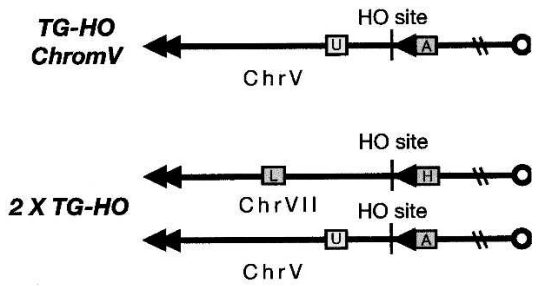

D

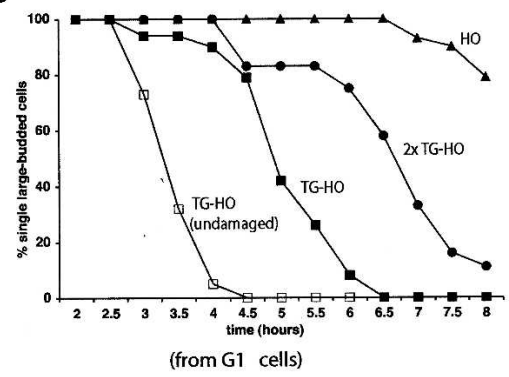


A
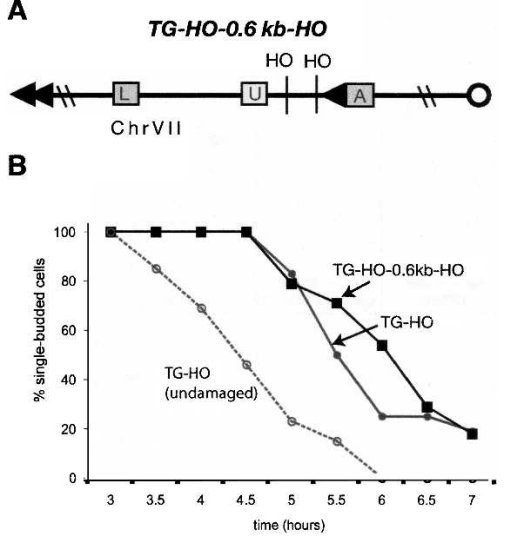

C

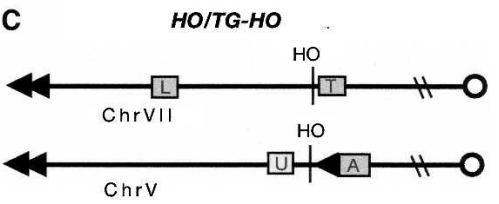

D

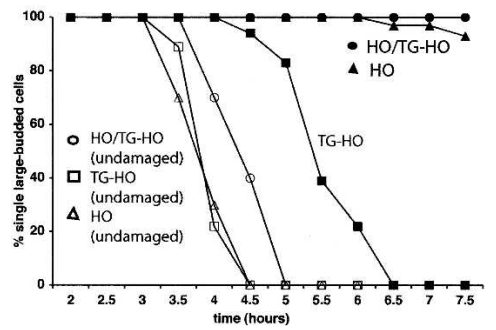

Figure 6. The anticheckpoint produces regional inhibition. $(A)$ Schematic diagram of ChromVII in the TG-HO 0.6-kb HO strain (RMY270). ( $\mathbf{\Delta}$ ) Telomeric repeats, (A) ADE2, (L) LYS2, and (U) URA3. (B) A second DSB $0.6 \mathrm{~kb}$ away from the $\mathrm{C}_{1-3} \mathrm{~A} / \mathrm{TG}_{1-3}$ repeats is subject to the anticheckpoint. TG-HO (RMY272) and TG-HO 0.6-kb HO (RMY270) were synchronized in $\alpha$ factor prior to induction with galactose and subsequently assayed for arrest as in Figure 1D. Quantitation of a Southern blot revealed that, of the cells that incurred a DSB, $\sim 67 \%$ had cuts at both HO sites, and $33 \%$ had a DSB at one or the other HO site. Thus, the majority of the cells contained two DSBs. (C) Schematic depiction of ChromV and ChromVII in the HO/TG-HO strain (RMY262). A HO site flanked by $\mathrm{C}_{1-3} \mathrm{~A} / \mathrm{TG}_{1-3}$ repeats was introduced into the HO bar 1 strain (RMY242) to create the $\mathrm{HO} /$ TG-HO strain (RMY262). (D) The normal DSB response is not inhibited by $\mathrm{C}_{1-3} \mathrm{~A} / \mathrm{TG}_{1-3}$ repeats on a separate chromosome. TG-HO (RMY241), HO (RMY242), and HO/TG-HO (RMY262) cells were synchronized in $\alpha$ factor prior to induction with galactose and subsequently assayed for arrest as in Figure 1C.

-125 bp by $4 \mathrm{~h}$ (Diede and Gottschling 1999). It was interesting, and implied a possible cause and effect, that the amount of time required before detectable telomerase activity and the length of arrest in the TG-HO strain were similar. Perhaps telomerase activity is required per se for the anticheckpoint activity. To test this hypothesis we examined the TG-HO strain after deleting the RNA subunit (TLC1) of telomerase. We found no difference in the length of the abridged arrest between TG-HO tlc1 and TG-HO TLC1+ strains (Fig. 7A). We also found that deletion of the Raplp-interacting-factor 2 (RIF2), which enhances telomere elongation, did not alter the abridged arrest in the TG-HO strain (Fig. 7B).

Finally, we tested whether telomere gene silencing, called telomere position effect (TPE), contributes to the abridged arrest. To test this hypothesis we needed to alter SIR gene function. Deleting SIR genes presented a technical difficulty; since they are also required for silencing at the mating loci, their disruption would lead to $\mathrm{HO}$ breaks at $H M L$ and $H M R$ as well. Therefore, instead of sir deletion mutants we used overexpression of a mutant sir2 that efficiently disrupts telomeric silencing but not mating-type silencing (Garcia and Pillus 2002). We examined the delay of the TG-HO cells containing plasmids that contained either vector alone, the wild-type SIR2, or a sir2-G270E that is dominant-negative for TPE. We found that there was no substantial difference in delay among these strains (Fig. 7C). Together the results in Figure 7 indicate that the anticheckpoint and abridged arrest is not influenced directly by telomerase activity or by telomeric gene silencing and heterochromatin mediated by Sir2.

\section{Discussion}

In this study we discovered that the checkpoint response produced by a DSB is inhibited by adjacent telomeric sequences (Fig. 1D). The initial checkpoint response of a DSB adjacent to the telomeric sequence in the TG-HO cells is virtually indistinguishable from that produced by a normal DSB; however, the checkpoint response is turned off relatively quickly (in 1-2 h) in TG-HO cells. This abridged arrest is not the result of repair of the DNA break (Fig. 1G) and is genetically distinct from the phenomenon known as adaptation (Fig. 3C,D). We believe this abridged arrest is likely due to the presence of an inhibitor because checkpoint signaling was inhibited from both the DNA fragment immediately adjacent to the new telomere (Fig. 1D) and a second DSB $0.6 \mathrm{~kb}$ away, but not from a distant DSB on a separate chromosome (Fig. 6B,D). The inhibitory activity on the checkpoint response occurs upstream of Rad9 and Rad53 (Fig. $2)$. Inhibition does not require telomerase and is not affected by disruption of TPE (Fig. 7).

\section{Potential mechanisms for checkpoint inhibition}

The mechanism of inhibition is currently unknown. One possible mechanism of inhibition could involve relocalization of the DSBs to the nuclear periphery, which we speculate may be inhibitory to checkpoint signaling. Telomeres and other heterochromatic DNA do localize to the nuclear periphery in interphase yeast cells (Gilson et al. 1993). Relocalization might account for the shortened, but intact, arrest response. However, this model is not consistent with some of our observations. While interphase yeast telomeres do localize to the nuclear periphery, mitotic telomeres do not (Hediger et al. 2002), and a TG-HO cell that received a break while synchro- 
A

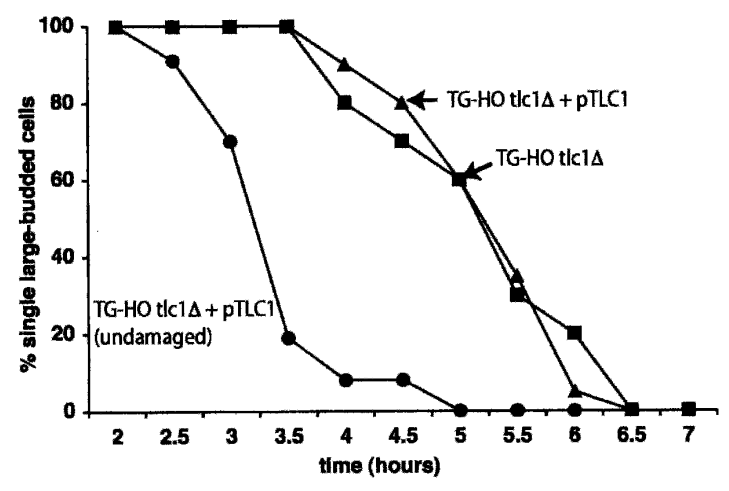

B

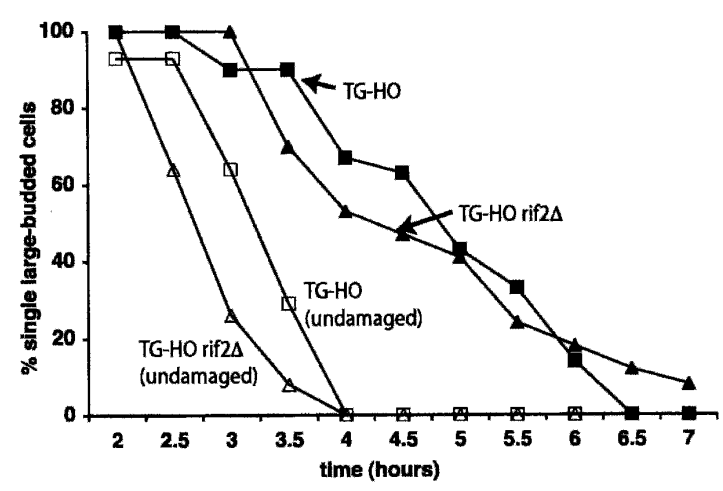

C

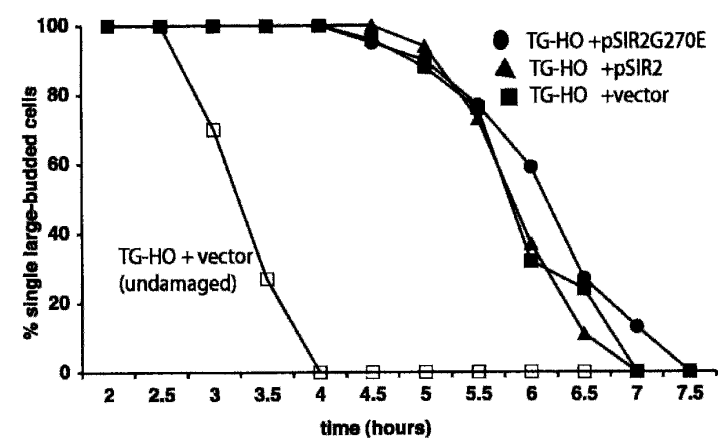

Figure 7. The anticheckpoint activity does not require telomerase, RIF2, or wild-type SIR2 activity. (A) The strain TG-HO tlc1s (UCC5961) was created from the TG-HO (UCC5913) strain by mutating TLC1, the RNA component of telomerase. TG-HO tlc1 $\Delta$, cells with or without a TLC1 complementation plasmid (i.e., "+pTLC1") were synchronized with nocodozole and analyzed for checkpoint arrest. (B) TG-HO (UCC5913) and TG-HO rif2 $\Delta$ (UCC5824) were synchronized with nocodozole and analyzed for checkpoint arrest. (C) A wild-type SIR2 CEN plasmid (pSir2), a dominant-negative sir2 CEN plasmid (psir2G270E), or an empty vector were transformed into the TG-HO bar 1 strain (RMY241). Each strain was synchronized with $\alpha$ factor prior to galactose induction of $\mathrm{HO}$ and analysis of checkpoint arrest as in Figure 1C.

nized in mitosis with nocodozole still produced an abridged arrest (Fig. 3B). Furthermore, the $K U$ genes are required for localization of telomeres to the nuclear pe- riphery, yet we still observe an abridged arrest in ku70 mutant strains (Fig. 3D). Thus, though it is unknown whether the chromosome ends in the TG-HO cells relocalize to the nuclear periphery, it appears unlikely that this mechanism would provide an explanation for the anticheckpoint activity.

Based on current models of checkpoint activation, we considered whether the abridged arrest in TG-HO cells might be because those cells contain less ssDNA compared with HO cells that exhibit a longer arrest. Less ssDNA is generated from one TG-HO break than from a normal $\mathrm{HO}$ break because the $\mathrm{C}_{1-3} \mathrm{~A} / \mathrm{TG}_{1-3}$ repeats prevent extensive resection on the telomeric side of the DSB (Diede and Gottschling 2001). There are several reasons why we believe that the amount of ssDNA does not explain the abridged arrest of the TG-HO strains. (1) The majority of TG-HO cells had already resumed the cell cycle by the time resection had begun, $1-2 \mathrm{~h}$ after $\mathrm{HO}$ cleavage (Figs. 1D, 4C; Frank-Vaillant and Marcand 2002). We therefore suggest that the anticheckpoint may be acting on the checkpoint even before substantial DNA degradation begins. (2) By holding TG-HO cells in mitosis with nocodozole for $3 \mathrm{~h}$ after the initiation of the DSB, the amount of ssDNA created by exonuclease resection would increase but arrest was not restored (Fig. $5 \mathrm{~A})$. We conclude that the anticheckpoint inactivates the checkpoint even when substantial amounts of ssDNA are present. Similarly, a ku70 deletion increases the rate of DSB resection (Lee et al. 1998) but did not relatively lengthen the delay of the TG-HO strain (Fig. 3D). (3) A second TG-HO site on a separate chromosome also did not increase the length of the delay to that caused by one normal HO break (Fig. 5D). Therefore, we believe that a decreased level of ssDNA in the TG-HO strains is not responsible for the abridged arrest.

We did find, however, that the 2xTG-HO cells with two DSBs near telomeric repeats arrested for longer than the TG-HO cells with one DSB near a telomeric repeat (Fig. 5D). This result may suggest something about the kinetics of recruitment of the anticheckpoint to a new telomere; perhaps a component required to form a new telomere and recruit the anticheckpoint activity is limiting in the cell. This model predicts that overexpression of the limiting component will result in an equally short abridged arrest in 2xTG-HO and TG-HO cells.

Another explanation for the abridged arrest involves removal of checkpoint signaling proteins from the site of damage by the $\mathrm{C}_{1-3} \mathrm{~A} / \mathrm{TG}_{1-3}$ repeats. Checkpoint proteins are known to interact with telomeres; they contribute to telomere maintenance (Mallory and Petes 2000), are required for the relocalization of some telomere proteins to the sites of DSBs (Martin et al. 1999; Mills et al. 1999|, and are associated directly with telomeres (at least in fission yeast; Nakamura et al. 2002). By this model, the $\mathrm{C}_{1-3} \mathrm{~A} / \mathrm{TG}_{1-3}$ repeats could act as a "sink" for checkpoint proteins, causing them to leave the site of the DSB, predicting that checkpoint proteins have a greater affinity for a telomere than for a nearby DSB. We do not favor this model because it is unclear to us how telomeres and a nearby DSB would compete for 
checkpoint proteins while a telomere and a distal DSB would not. We currently favor a simpler hypothesis that an anticheckpoint protein is recruited to telomeres during its formation, as discussed next.

Toward the molecular identity of the anticheckpoint: telomere 'maturation,' but not elongation, is required for the anticheckpoint

We suggest that a form of "telomere maturation" is required to achieve the inhibition of the checkpoint response (see model, Fig. 8). "Maturation" may involve the recruitment of protein factors to the $\mathrm{C}_{1-3} \mathrm{~A} / \mathrm{TG}_{1-3}$ repeats that then inhibit checkpoint signaling. The protein(s) responsible for inhibition is not known, but we do know that inhibition does not require telomerase (Fig. $7 \mathrm{~A}$ ), and therefore any lengthening ("healing") of the $\mathrm{C}_{1-3} \mathrm{~A} / \mathrm{TG}_{1-3}$ repeats is not essential for the anticheckpoint. We have also tested strains mutated or compromised for several telomere-associated proteins; disrupting KU70 (Fig. 3D), KU80 (data not shown), TLC1, RIF2, or expressing a dominant-negative SIR2 (Fig. 7) does not appreciably affect the abridged arrest, and so these proteins do not encode or regulate the putative inhibitor.

There are other candidate proteins that may constitute the anticheckpoint. The results in Figure 2 suggest that the anticheckpoint acts before Rad9 and Rad53, implying inhibition of Mec1. The mammalian telemore-binding protein TRF2 can inactivate another PIKK molecule, ATM, so TRF2 is a potential telomeric-anticheckpoint protein (Karlseder et al. 2004). While there is no yeast ortholog for TRF2, the general mechanism may be conserved between yeast and mammals that might use different specific inhibitors. Chief among the yeast candidate proteins are Cdc13, Rap1, Tbf1, and Tel2; all four are telomere-associated and essential for life, criteria for a putative anticheckpoint protein (Berman et al. 1986;

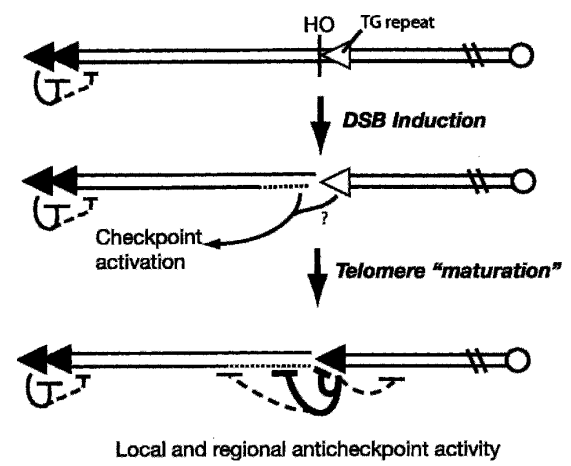

Figure 8. Model of telomere maturation and anticheckpoint activity. After a DSB is created adjacent to a telomere, a DNA damage checkpoint delay is initiated from one or both sides of the DSB. Over the course of $\sim 1-2 \mathrm{~h}$ the newly generated telomere end "matures" by recruiting protein factors that include the anticheckpoint, which blocks signaling from the telomere and nearby damage. The anticheckpoint exists constitutively at normal telomeres.
Liu and Tye 1991; Runge and Zakian 1996). Cdc13 is a particularly interesting telomeric protein that could directly or indirectly regulate the anticheckpoint response. CDC13 encodes an ssDNA-binding protein that recognizes telomere sequences and then recruits the telomerase subunit, Est1, to telomere ends (Bianchi et al. 2004). Interestingly, the recruitment of $\mathrm{Cdc13}$ to the $\mathrm{C}_{1-3} \mathrm{~A} /$ $\mathrm{TG}_{1-3}$ repeat is complete $\sim 60-90 \mathrm{~min}$ after cleavage at HO (Diede and Gottschling 2001), the time when the anticheckpoint becomes active. This suggests a Cdc13-dependent anticheckpoint mechanism. Which, if any, of these telomere-associated proteins is involved in mechanism of the anticheckpoint will require further study.

The role of the Rad50/Mre11/Xrs2 (MRX) complex in G2/M arrest

We found that RAD50 and MRE11 are absolutely required for the DSB-induced G2/M delay in both the TG$\mathrm{HO}$ and the wild-type $\mathrm{HO}$ strain (Fig. 4D,E; data not shown). The requirement of RAD50/MRE11 for G2/M arrest was absolute, regardless of the cell cycle stage in which the damage was induced (Fig. 4; data not shown). Others have reported only a partial role for the MRX complex in DSB signaling (for review, see van den Bosch et al. 2003). It is unclear to us why we detect an absolute requirement for the MRX complex in arrest not previously reported. Nevertheless, our results support the proposal that the MRX complex acts as a key primary sensor of DSBs (Petrini and Stracker 2003).

\section{The anticheckpoint and repeat sequences near telomeres}

We believe that the anticheckpoint most likely exists to prevent healthy telomeres from constitutively activating checkpoint signaling. While the presence of a telomeric anticheckpoint may allow cell division, it may also have other negative consequences. Because checkpoint signaling is attenuated from a DSB $0.6 \mathrm{~kb}$ away from a telomere as well as at the telomere (Fig. 6B), it is possible that DNA sequences adjacent to normal telomeres that suffer a DSB (or a stalled replication fork) might not experience the benefit of checkpoint controls to assist in coordinating repair. In other words, the anticheckpoint's "regional inhibition" may render DNA sequences near telomeres constitutively checkpoint-defective. In this regard it might be interesting that sequences near normal telomeres consist of repeat sequences on all eukaryotic chromosomes (for review, see Louis 1995; Zakian 1996). We suggest that these subtelomeric repeat sequences may, because of their high copy number and proximity, allow efficient repair of DNA breaks near the telomere. The subtelomeric repeats may thus provide a mechanism of repair, and thus genome stability, to compensate for the lack of checkpoint signaling near telomeres. 


\section{Materials and methods}

Yeast strains and plasmids

The genotypes of all yeast strains used in this study are listed in Table 1 . The $2 \mu$ plasmids containing $R N R 1$ were provided by $\mathrm{L}$. Vallen and F. Cross (Rockefeller University, New York; pers. comm.) or S. Elledge (Baylor College, Houston, TX) (Desany et al. 1998). The plasmid pTAK181x6 for Flag-RAD53 epitope tagging was kindly provided by J. Petrini (Sloan Kettering, New York). The CEN plasmids containing the wild-type SIR2 gene and the dominant-negative sir2-G270E allele were a gift from L. Pillus (University of California at San Diego, San Diego, CA). All other plasmids carrying alleles in yeast or for creating deletions are derived from the "pRS" plasmids that have been previously described (Sikorski and Hieter 1989). One-thousand base pairs of ChromVII $(12,000-13,000)$ was subcloned into the KpnI site of pRS406 to create plasmid pRM1. PCR was used to amplify and subclone the HO-TRP1 cassette from RMY169 into plasmid pRM1 to create pRM2.

All the yeast strains are derivatives of the strain UCC5913 (Diede and Gottschling 2001) donated by D. Gottschling (Fred Hutchinson Cancer Center, Seattle, WA). Strain RMY169 was created by replacing the ADE2-TG(1-3) cassette with TRP1 using PCR recombination as described (Longtine et al. 1998). A cross between UCC5691 (Diede and Gottschling 1999) and UCC5913 was sporulated to create RMY195. The dun1s, $\operatorname{chk} 1 \Delta$, mec1s, and $c d c 5$-ad alleles were integrated into yeast strains by transformation (Schiestl and Gietz 1989) and/or genetic crosses. After transformation, mutants were selected by prototrophy, appropriate phenotypes confirmed, and genomic structures verified by PCR or Southern blot. RMY178 was constructed by first subcloning the SacI fragment of pTAK181x6 into pRS404 and cutting with SphI prior to transformation. RMY199 was created using PCR amplification of the rad50::KanMX locus in UCC8000 and transformation into RMY169. RMY201 was created by transforming RMY169 with pJH31 (a gift from J. Haber, Brandeis, Boston, MA). RMY218 is a segregant from a cross between RMY201 and RMY154. RMY231 was created in two steps. The URA3 gene was directed to the CAN1 gene by first amplifying CAN1 using the primers bam-CAN1-for (CGGGATCCCAAAAGAAGACGC CGACATAGA) and bam-CAN1-rev (CGGGATCCCTACAA CATTCCAAAATTTGTCCC), cloning into the BamHI site of pRS406, cutting with BglII, and transforming RMY195. Secondly, the ADE2-TG(1-3) cassette was inserted into the NPR2 locus using fusion PCR (Kitazono et al. 2002) and the primers $5^{\prime} N P R 2$ la (AACTCCACAACAA CACCCTCCAC) and 5'NPR2 Ib (CGAAGTTTTGATGAGCCACACAGCGGGGCACATCTT CTAATGAGACAC) for the $5^{\prime}$ end homology with NPR2; 3'NPR2 2a (CAGTAACAACGTTGGATCCGACCCCTCAAAA CTCCTCCTTAAATTCCTC) and 3'NPR2 2b (AATACCTT CTTCTTCGTCGCTG) for the 3' end homology with NPR2; and XhoIpsd158 rev (GGGTCGGATCCAACGTTGTTACTG) for the fusion of the $5^{\prime}$ NPR2 homology with the ADE2-TG(1-3) from strain UCC5913. The process for creating RMY232 was the same as for RMY231 except UCC5913 was the parent strain. The BAR1 gene was deleted in the strains UCC5913 and RMY169 using the plasmid pJGsst1 (from D. Lydall, University of Newcastle, Newcastle, UK) to create RMY241 and RMY242, respectively. RMY223 was created by replacing ADE2 with HIS3 using PCR recombination (Longtine et al. 1998). RMY233 was constructed in the exact same manner as RMY231 except RMY223 was used as the parent strain. RMY250 is a segregant from a cross between RMY201 and RMY233. RMY238 was derived from RMY232, in which URA3 on ChromV was replaced by the TRP1 gene, and barl was mutated using pJGsst1 (from D.
Lydall). RMY270 and RMY272 were made by PCR transformation of a PCR product integrating either HO-URA3 (RMY270) or URA3 alone (RMY272) into ChromVII at base $\sim 14,500$. The HO site was inserted into EcoR1 sites of pRS406 to generate the pRS406-HO site that contains 333 bp of ChromIII (ChromIII, 20,0670-21,003) of the MAT $\alpha$ sequence. To amplify HO-URA3 or URA3 alone, PCR reactions were carried out using two primers: The first consisted of 5' ChromVII sequence $(14,369-14,317)$ and $3^{\prime}$ pRS406 sequence (299-313), and the second 5' ChromVII sequence $(14,668-14,621)$ and 3' pRS406 sequence (2301-2283). PCR reactions were carried out using either pRS406-HO site or pRS406. BAR1 was mutated by PCR recombination in RMY250 to create RMY262 and in UCC5894 to create RMY258.

\section{HO induction and cell cycle arrest}

Strains were grown overnight in complete media lacking amino acids required to maintain the left arm of ChromVII (-lys) or ChromV (-ura) plus $2 \%$ sucrose at $30^{\circ} \mathrm{C}$. The following morning stationary phase cells were then centrifuged and resuspended in rich media $(\mathrm{YEP})+2 \%$ sucrose at $\sim 1 \times 10^{7}$ cells $/ \mathrm{mL}$ and incubated for $60 \mathrm{~min}$ at $30^{\circ} \mathrm{C}$ to resume cycling. The cells were then split: One culture was used for sucrose controls, and the other culture was washed with warm YEP media without sugar, then resuspended in YEP $+3 \%$ galactose to induce $\mathrm{HO}$ endonuclease and incubated for $60 \mathrm{~min}$ at $30^{\circ} \mathrm{C}$. For synchronized culture experiments, prior to switching to galactose, either nocodozole (9 $\mathrm{\mu g} / \mathrm{mL}$ of nocodozole in $1 \%$ dimethylsulfoxide) or $\alpha$ factor $\left(4 \times 10^{-5} \mathrm{mg} / \mathrm{mL}\right)$ was added for G2 or G1 synchronization, respectively. The cells were then centrifuged and resuspended in YEP $+2 \%$ glucose and spread on YEP $+2 \%$ glucose agar plates and dissected into a grid for analysis. For each strain usually 30-40 individual cells were analyzed. For example, for the TGHO cells in Figure 1D, 19 cells were Lys- and thus scored as have a DNA break, seven cells were Lys+ and were thus treated as cells that did not have a DNA break, and four cells died (usually as a single-budded cell) and were not incorporated into either set of data. For the TG-HO 0.6kb-HO strain in Figure 6B, 28 cells became Lys- and were scored as having a DNA break, six cells remained Lys+ and were scored as not having a DNA break, and eight cells died.

\section{Western blots, Southern blots, and gel-shift assays}

For Western blots and kinase assays the yeast cells used were propagated and treated identically to the cell cycle arrest assay. After centrifugation, the proteins were prepared using a TCA precipitation technique (Longhese et al. 1997) before resolving on $8 \%$ SDS-polyacrylamide gels. Proteins were transferred to nitrocellulose (Bio-Rad) for Western blots or PVDF for kinase assays (Bio-Rad) according to the manufacturer. To detect FlagRad53 a monoclonal Flag antibody was used at 1:400 dilution (Sigma) followed by a monoclonal secondary antibody that was visualized following the manufacturer's recommendations (Pierce). The kinase assay was performed as described by Pellicioli et al. (1999). The preparation of genomic DNA for PCR or Southern blot has been previously described (Hoffman and Winston 1987). The DNAs were separated on $1 \%$ agarose-TBE gels and transferred to Genescreen nylon filters (Dupont) as directed by the manufacturer. The riboprobe template was created by PCR-cloning a 346-bp fragment of ChromVII using the primers ATGGATCCAGAAATCAATCAAGAAGTCCCTTAGTC and ATGAATTCGCCATCATCACAAACACTGCTAAC and inserting into BamHI/EcoRI of pRS423. The riboprobes to detect Watson or Crick strands were created by using either T3 (RiboT3, Crick detection) or T7 RNA polymerase (RiboT7, Watson detection), respectively, following the procedure of the manufacturer (Roche). 
Table 1. Yeast strains used in this study

\begin{tabular}{|c|c|c|}
\hline Strain & Genotype & Source \\
\hline DSY233 & $\begin{array}{l}\text { Mata-inc ura3-52 lys2-801 ade2-101 ochre trp1-d63 his3-d200 leu2-d1:GAL1-HO-LEU2 } \\
\text { VII-L::TRP-HO site-LYS2 sml1::KanMX4 mec1::URA3 }\end{array}$ & David Schwartz \\
\hline RMY144 & $\begin{array}{l}\text { Mata-inc ura3-52 lys2-801 ade2-101 ochre trp1-d63 his3-d200 leu2-d1:GAL1-HO-LEU2 } \\
\text { VII-L::ADE2-TG(1-3)-HO site-LYS2 } \\
\text { p2 } \mu \text { RNR1-TRP1 } \\
\text { mec1::URA3 }\end{array}$ & \\
\hline RMY154 & $\begin{array}{l}\text { Mata-inc ura3-52 lys2-801 ade2-101 ochre trp1-d63 his3-d200 leu2-d1:GAL1-HO-LEU2 } \\
\text { VII-L::ADE2-TG(1-3)-HO site-LYS2 } \\
\text { cdc5-ad::URA3 }\end{array}$ & This study \\
\hline RMY169 & $\begin{array}{l}\text { Mata-inc ura3-52 lys2-801 ade2-101 ochre trp1-d63 his3-d200 leu2-d1:GAL1-HO-LEU2 } \\
\text { VII-L::TRP-HO site-LYS2 }\end{array}$ & This study \\
\hline RMY170 & $\begin{array}{l}\text { Mata-inc ura3-52 lys2-801 ade2-101 ochre trp1-d63 his3-d200 leu2-d1:GAL1-HO-LEU2 } \\
\text { VII-L::ADE2-TG(1-3)-HO site-LYS2 } \\
\text { dun1:HIS }\end{array}$ & This study \\
\hline RMY171 & $\begin{array}{l}\text { Mata-inc ura3-52 lys2-801 ade2-101 ochre trp1-d63 his3-d200 leu2-d1:GAL1-HO-LEU2 } \\
\text { VII-L::ADE2-TG(1-3)-HO site-LYS2 } \\
\text { chk1:HIS }\end{array}$ & This study \\
\hline RMY178 & $\begin{array}{l}\text { Mata-inc ura3-52, lys2-801, ade2-101ochre, tryp1-d63, his3-d200, } \\
\text { leu2-dl:GAL1-HO-LEU2, VII-L::ADE2-TG(1-3)-HO, site-LYS2 RAD53-FLAG::HIS3 }\end{array}$ & This study \\
\hline RMY195 & $\begin{array}{l}\text { Mata-inc ura3-52, lys2-801, ade2-101ochre, tryp1-d63, his3-d200, } \\
\text { leu2-dl:GAL1-HO-LEU2, VII-L site-LYS2 }\end{array}$ & This study \\
\hline RMY199 & $\begin{array}{l}\text { Mata-inc ura3-52 lys2-801 ade2-101 ochre trp1-d63 his3-d200 leu2-d1:GAL1-HO-LEU2 } \\
\text { VII-L::TRP-HO site-LYS2, rad50A::KANMX4 }\end{array}$ & This study \\
\hline RMY201 & $\begin{array}{l}\text { Mat } \alpha \text {-inc ura3-52 lys2-801 ade2-101 ochre trp1-d63 his3-d200 leu2-dl:GAL1-HO-LEU2 } \\
\text { VII-L::TRP-HO site-LYS2 }\end{array}$ & This study \\
\hline RMY218 & $\begin{array}{l}\text { Mata-inc ura3-52 lys2-801 ade2-101 ochre trp1-d63 his3-d200 leu2-d1:GAL1-HO-LEU2 } \\
\text { VII-L::TRP-HO site-LYS2, cdc5-ad:URA3 }\end{array}$ & This study \\
\hline RMY223 & $\begin{array}{l}\text { Mata-inc ura3-52 lys2-801 ade2-101 ochre trp1-d63 his3-d200 leu2-d1:GAL1-HO-LEU2 } \\
\text { VII-L::ade2::HIS3-TG(1-3)-HO site-LYS2 }\end{array}$ & This study \\
\hline RMY231 & $\begin{array}{l}\text { Mata-inc ura3-52, lys2-801, ade2-101ochre, tryp1-d63, his3-d200, } \\
\text { leu2-dl:GAL1-HO-LEU2, VII-L site-LYS2 } \\
\text { CAN1::URA3::can1 } \\
\text { npr2::ADE2-TG1-3-HO }\end{array}$ & This study \\
\hline RMY232 & $\begin{array}{l}\text { Mata-inc ura3-52 lys2-801 ade2-101 ochre trp1-d63 his3-d200 leu2-d1:GAL1-HO-LEU2 } \\
\text { VII-L::ade2::HIS3-TG(1-3)-HO site-LYS2 } \\
\text { CAN1::URA3::can1 } \\
\text { npr2::ADE2-TG1-3-HO }\end{array}$ & This study \\
\hline RMY238 & $\begin{array}{l}\text { Mata-inc ura3-52 lys2-801 ade2-101 ochre trp1-d63 his3-d200 leu2-d1:GAL1-HO-LEU2 } \\
\text { VII-L::ade2::HIS3-TG(1-3)-HO site-LYS2 } \\
\text { CAN1::TRP1 } \\
\text { npr2::ADE2-TG1-3-HO } \\
\text { bar1 }:: \text { hisg }\end{array}$ & This study \\
\hline RMY241 & $\begin{array}{l}\text { Mata-inc ura3-52 lys2-801 ade2-101 ochre trp1-d63 his3-d200 leu2-d1:GAL1-HO-LEU2 } \\
\text { VII-L::ADE2-TG(1-3)-HO site-LYS2 } \\
\text { bar1::hisg }\end{array}$ & This study \\
\hline RMY242 & $\begin{array}{l}\text { Mata-inc ura3-52 lys2-801 ade2-101 ochre trp1-d63 his3-d200 leu2-d1:GAL1-HO-LEU2 } \\
\text { VII-L::TRP-HO site-LYS2 bar1::hisg }\end{array}$ & This study \\
\hline RMY250 & $\begin{array}{l}\text { Mata-inc ura3-52 lys2-801 ade2-101 ochre trp1-d63 his3-d200 leu2-d1:GAL1-HO-LEU2 } \\
\text { VII-L::TRP-HO site-LYS2 } \\
\text { CAN1::URA3::can1 } \\
\text { npr2::ADE2-TG1-3-HO }\end{array}$ & This study \\
\hline RMY258 & $\begin{array}{l}\text { Mata-inc ura3-52 lys2-801 ade2-101 ochre trp1-d63 his3-d200 leu2-d1:GAL1-HO-LEU2 } \\
\text { VII-L::ADE2-TG(1-3)-HO site-LYS2, rad52::hisG } \\
\text { ku70:HIS3 } \\
\text { bar1::URA3::hisG }\end{array}$ & $\begin{array}{l}\text { Dan Gottschling; } \\
\text { this study }\end{array}$ \\
\hline RMY262 & $\begin{array}{l}\text { Mata-inc ura3-52 lys2-801 ade2-101 ochre trp1-d63 his3-d200 leu2-d1:GAL1-HO-LEU2 } \\
\text { VII-L::TRP-HO site-LYS2 } \\
\text { CAN1::URA3::can1 } \\
\text { npr2::ADE2-TG1-3-HO } \\
\text { bar1::KANMX }\end{array}$ & This study \\
\hline
\end{tabular}


Michelson et al.

Table 1. (continued)

\begin{tabular}{|c|c|c|}
\hline Strain & Genotype & Source \\
\hline RMY270 & $\begin{array}{l}\text { Mata-inc ura3-52 lys2-801 ade2-101 ochre trp1-d63 his3-d200 leu2-d1:GAL1-HO-LEU2 } \\
\text { VII-L::ADE2-TG(1-3)-HO site-LYS2 } \\
\text { bar1::hisg } \\
\text { VII-14,369-URA3-HO site-14621 }\end{array}$ & This study \\
\hline RMY272 & $\begin{array}{l}\text { Mata-inc ura3-52 lys2-801 ade2-101 ochre trp1-d63 his3-d200 leu2-d1:GAL1-HO-LEU2 } \\
\text { VII-L::ADE2-TG(1-3)-HO site-LYS2 } \\
\text { bar1::hisg } \\
\text { VII-14,369-URA3-14621 } \\
\text { rad52::HIS3 }\end{array}$ & This study \\
\hline UCC5706 & $\begin{array}{l}\text { MATa-inc ura3-52 lys2-801 ade2-101 trp1-D63 his3-D200 leu2-D1:GAL1-HO-LEU2 } \\
\text { VII-L::ADE2-TG(1-3)-HO site-LYS2 rad52:hisg }\end{array}$ & Dan Gottschling \\
\hline UCC5824 & $\begin{array}{l}\text { MATa-inc ura3-52 lys2-801 ade2-101 trp1-D63 his3-D200 leu2-D1:GAL1-HO-LEU2 } \\
\text { VII-L::ADE2-TG(1-3)-HO site-LYS2 rad52::hisg rif2::HIS3 }\end{array}$ & Dan Gottschling \\
\hline UCC5894 & $\begin{array}{l}\text { MATa-inc ura3-52 lys2-801 ade2-101 trp1-D63 his3-D200 leu2-D1:GAL1-HO-LEU2 } \\
\text { VII-L::ADE2-TG(1-3)-HO site-LYS2 rad52::hisG, pCEN-RAD52-TRP1 }\end{array}$ & Dan Gottschling \\
\hline UCC5913 & $\begin{array}{l}\text { MATa-inc ura3-52 lys2-801 ade2-101 trp1-D63 his3-D200 leu2-D1:GAL1-HO-LEU2 } \\
\text { VII-L::ADE2-TG(1-3)-HO site-LYS2 }\end{array}$ & $\begin{array}{l}\text { Diede and } \\
\quad \text { Gottschling } 2001\end{array}$ \\
\hline UCC5961 & $\begin{array}{l}\text { MATa-inc ura3-52 lys2-801 ade2-101 trp1-D63 his3-D200 leu2-D1:GAL1-HO-LEU2 } \\
\text { VII-L::ADE2-TG(1-3)-HO site-LYS2 tlc1::HIS3 pTLC1-URA3 }\end{array}$ & $\begin{array}{l}\text { Diede and } \\
\text { Gottschling } 2001\end{array}$ \\
\hline UCC 8000 & $\begin{array}{l}\text { MATa-inc ura3-52 lys2-801 ade2-101 trp1-D63 his3-D200 leu2-D1:GAL1-HO-LEU2 } \\
\text { VII-L::ADE2-TG(1-3)-HO site-LYS2 rad50 } 4 \text { KanMX4 }\end{array}$ & $\begin{array}{l}\text { Diede and } \\
\text { Gottschling } 2001\end{array}$ \\
\hline
\end{tabular}

\section{Acknowledgments}

We thank S. Diede and D. Gottschling for advice and for providing a wonderful system for studying this phenomenon. We also thank the MCB department and members of our lab for creative discussions, and J. Haber, J. Petrini, L. Pillus, D. Schwartz, and D. Lydall for donating strains and/or plasmids. This work was supported by a Damon Runyon Cancer Research Fellowship (\#DRG1586) to R.J.M. and a National Science Foundation Grant (\#0222193) to T.W.

\section{References}

Berman, J., Tachibana, C.Y., and Tye, B.K. 1986. Identification of a telomere-binding activity from yeast. Proc. Natl. Acad. Sci. 83: 3713-3717.

Bianchi, A., Negrini, S., and Shore, D. 2004. Delivery of yeast telomerase to a DNA break depends on the recruitment functions of Cdc13 and Est1. Mol. Cell 16: 139-146.

D'Adda Di Fagagna, F., Teo, S.H., and Jackson, S.P. 2004. Functional links between telomeres and proteins of the DNAdamage response. Genes \& Dev. 18: 1781-1799.

Desany, B.A., Alcasabas, A.A., Bachant, J.B., and Elledge, S.J. 1998. Recovery from DNA replicational stress is the essential function of the S-phase checkpoint pathway. Genes \& Dev. 12: 2956-2970.

Diede, S.J. and Gottschling, D.E. 1999. Telomerase-mediated telomere addition in vivo requires DNA primase and DNA polymerases $\alpha$ and $\delta$. Cell 99: 723-733.

- 2001. Exonuclease activity is required for sequence addition and Cdc13p loading at a de novo telomere. Curr. Biol. 11: $1336-1340$.

Dionne, I. and Wellinger, R.J. 1996. Cell cycle-regulated generation of single-stranded G-rich DNA in the absence of telomerase. Proc. Nat1. Acad. Sci. 93: 13902-13907.

Ferreira, M.G., Miller, K.M., and Cooper, J.P. 2004. Indecent exposure: When telomeres become uncapped. Mol. Cell 13: $7-18$.
Frank-Vaillant, M. and Marcand, S. 2002. Transient stability of DNA ends allows nonhomologous end joining to precede homologous recombination. Mol. Cell 10: 1189-1199.

Garcia, S.N. and Pillus, L. 2002. A unique class of conditional sir2 mutants displays distinct silencing defects in Saccharomyces cerevisiae. Genetics 162: 721-736.

Gardner, R., Putnam, C.W., and Weinert, T. 1999. RAD53, DUN1 and PDS1 define two parallel G2/M checkpoint pathways in budding yeast. EMBO J. 18: 3173-3185.

Garvik, B., Carson, M., and Hartwell, L. 1995. Single-stranded DNA arising at telomeres in cdc13 mutants may constitute a specific signal for the RAD9 checkpoint. Mol. Cell. Biol. 15: 6128-6138.

Gilson, E., Laroche, T., and Gasser, S.M. 1993. Telomeres and the functional architecture of the nucleus. Trends Cell Biol. 3: $128-134$.

Greenwell, P.W., Kronmal, S.L., Porter, S.E., Gassenhuber, J., Obermaier, B., and Petes, T.D. 1995. TEL1, a gene involved in controlling telomere length in $S$. cerevisiae, is homologous to the human ataxia telangiectasia gene. Cell 82: 823829.

Hande, M.P., Balajee, A.S., Tchirkov, A., Wynshaw-Boris, A., and Lansdorp, P.M. 2001. Extra-chromosomal telomeric DNA in cells from Atm ${ }^{-/-}$mice and patients with ataxiatelangiectasia. Hum. Mol. Genet. 10: 519-528.

Hartwell, L.H. and Weinert, T.A. 1989. Checkpoints: Controls that ensure the order of cell cycle events. Science 246: 629634.

Hediger, F., Neumann, F.R., Van Houwe, G., Dubrana, K., and Gasser, S.M. 2002. Live imaging of telomeres: yKu and Sir proteins define redundant telomere-anchoring pathways in yeast. Curr. Biol. 12: 2076-2089.

Hoffman, C.S. and Winston, F. 1987. A ten-minute DNA preparation from yeast efficiently releases autonomous plasmids for transformation of Escherichia coli. Gene 57: 267-272.

IJpma, A.S. and Greider, C.W. 2003. Short telomeres induce a DNA damage response in Saccharomyces cerevisiae. Mol. Biol. Cell 14: 987-1001. 
Karlseder, J., Hoke, K., Mirzoeva, O.K., Bakkenist, C., Kastan, M.B., Petrini, J.H., and de Lange, T. 2004. The telomeric protein TRF2 binds the ATM kinase and can inhibit the ATM-dependent DNA damage response. PLoS Biol. 2: E240.

Kitazono, A.A., Tobe, B.T., Kalton, H., Diamant, N., and Kron, S.J. 2002. Marker-fusion PCR for one-step mutagenesis of essential genes in yeast. Yeast 19: 141-149.

Kolodner, R.D., Putnam, C.D., and Myung, K. 2002. Maintenance of genome stability in Saccharomyces cerevisiae. Science 297: 552-557.

Lee, S.E., Moore, J.K., Holmes, A., Umezu, K., Kolodner, R.D., and Haber, J.E. 1998. Saccharomyces Ku70, mre11/rad50 and RPA proteins regulate adaptation to G2/M arrest after DNA damage. Cell 94: 399-409.

Liu, Z.P. and Tye, B.K. 1991. A yeast protein that binds to vertebrate telomeres and conserved yeast telomeric junctions. Genes \& Dev. 5: 49-59.

Longhese, M.P., Paciotti, V., Fraschini, R., Zaccarini, R., Plevani, P., and Lucchini, G. 1997. The novel DNA damage checkpoint protein ddclp is phosphorylated periodically during the cell cycle and in response to DNA damage in budding yeast. EMBO J. 16: 5216-5226.

Longtine, M.S., McKenzie III, A., Demarini, D.J., Shah, N.G., Wach, A., Brachat, A., Philippsen, P., and Pringle, J.R. 1998. Additional modules for versatile and economical PCR-based gene deletion and modification in Saccharomyces cerevisiae. Yeast 14: 953-961.

Louis, E.J. 1995. The chromosome ends of Saccharomyces cerevisiae. Yeast 11: 1553-1573.

Lydall, D. and Weinert, T. 1995. Yeast checkpoint genes in DNA damage processing: Implications for repair and arrest. Science 270: 1488-1491.

Mallory, J.C. and Petes, T.D. 2000. Protein kinase activity of Tellp and Meclp, two Saccharomyces cerevisiae proteins related to the human ATM protein kinase. Proc. Natl. Acad. Sci. 97: 13749-13754.

Marcand, S., Brevet, V., Mann, C., and Gilson, E. 2000. Cell cycle restriction of telomere elongation. Curr. Biol. 10: 487490.

Martin, S.G., Laroche, T., Suka, N., Grunstein, M., and Gasser, S.M. 1999. Relocalization of telomeric Ku and SIR proteins in response to DNA strand breaks in yeast. Cell 97: 621-633.

Maser, R.S. and DePinho, R.A. 2004. Telomeres and the DNA damage response: Why the fox is guarding the henhouse. DNA Repair (Amst.) 3: 979-988.

Metcalfe, J.A., Parkhill, J., Campbell, L., Stacey, M., Biggs, P., Byrd, P.J., and Taylor, A.M. 1996. Accelerated telomere shortening in ataxia telangiectasia. Nat. Genet. 13: 350-353.

Mills, K.D., Sinclair, D.A., and Guarente, L. 1999. MEC1-dependent redistribution of the Sir3 silencing protein from telomeres to DNA double-strand breaks. Cell 97: 609-620.

Nakamura, T.M., Moser, B.A., and Russell, P. 2002. Telomere binding of checkpoint sensor and DNA repair proteins contributes to maintenance of functional fission yeast telomeres. Genetics 161: 1437-1452.

Nyberg, K.A., Michelson, R.J., Putnam, C.W., and Weinert, T.A. 2002. Toward maintaining the genome: DNA damage and replication checkpoints. Annu. Rev. Genet. 36: 617-656.

Pellicioli, A., Lucca, C., Liberi, G., Marini, F., Lopes, M., Plevani, P., Romano, A., Di Fiore, P.P., and Foiani, M. 1999. Activation of Rad53 kinase in response to DNA damage and its effect in modulating phosphorylation of the lagging strand DNA polymerase. EMBO J. 18: 6561-6572.

Petrini, J.H. and Stracker, T.H. 2003. The cellular response to DNA double-strand breaks: Defining the sensors and mediators. Trends Cell Biol. 13: 458-462.
Raghuraman, M.K., Winzeler, E.A., Collingwood, D., Hunt, S., Wodicka, L., Conway, A., Lockhart, D.J., Davis, R.W., Brewer, B.J., and Fangman, W.L. 2001. Replication dynamics of the yeast genome. Science 294: 115-121.

Rouse, J. and Jackson, S.P. 2002. Interfaces between the detection, signaling, and repair of DNA damage. Science 297: 547-551.

Runge, K.W. and Zakian, V.A. 1996. TEL2, an essential gene required for telomere length regulation and telomere position effect in Saccharomyces cerevisiae. Mol. Cell. Biol. 16: 3094-3105.

Sanchez, Y., Desany, B.A., Jones, W.J., Liu, Q., Wang, B., and Elledge, S.J. 1996. Regulation of RAD53 by the ATM-like kinases MEC1 and TEL1 in yeast cell cycle checkpoint pathways. Science 271: 357-360.

Sanchez, Y., Bachant, J., Wang, H., Hu, F., Liu, D., Tetzlaff, M., and Elledge, S.J. 1999. Control of the DNA damage checkpoint by chk1 and rad53 protein kinases through distinct mechanisms. Science 286: 1166-1171.

Sandell, L.L. and Zakian, V.A. 1993. Loss of a yeast telomere: Arrest, recovery, and chromosome loss. Cell 75: 729-739.

Schiestl, R.H. and Gietz, R.D. 1989. High efficiency transformation of intact yeast cells using single stranded nucleic acids as a carrier. Curr. Genet. 16: 339-346.

Sikorski, R.S. and Hieter, P. 1989. A system of shuttle vectors and yeast host strains designed for efficient manipulation of DNA in Saccharomyces cerevisiae. Genetics 122: 19-27.

Takata, H., Kanoh, Y., Gunge, N., Shirahige, K., and Matsuura, A. 2004. Reciprocal association of the budding yeast ATMrelated proteins Tell and Mecl with telomeres in vivo. Mol. Cell 14: 515-522.

Tercero, J.A. and Diffley, J.F. 2001. Regulation of DNA replication fork progression through damaged DNA by the Mec1/ Rad53 checkpoint. Nature 412: 553-557.

Toczyski, D.P., Galgoczy, D.J., and Hartwell, L.H. 1997. CDC5 and CKII control adaptation to the yeast DNA damage checkpoint. Cell 90: 1097-1106.

van den Bosch, M., Bree, R.T., and Lowndes, N.F. 2003. The MRN complex: Coordinating and mediating the response to broken chromosomes. EMBO Rep. 4: 844-849.

Viscardi, V., Baroni, E., Romano, M., Lucchini, G., and Longhese, M.P. 2003. Sudden telomere lengthening triggers a Rad53-dependent checkpoint in Saccharomyces cerevisiae. Mol. Biol. Cell 14: 3126-3143.

Zakian, V.A. 1996. Structure, function, and replication of Saccharomyces cerevisiae telomeres. Annu. Rev. Genet. 30: 141-172.

Zhou, B.B. and Elledge, S.J. 2000. The DNA damage response: Putting checkpoints in perspective. Nature 408: 433-439.

Zou, L. and Elledge, S.J. 2003. Sensing DNA damage through ATRIP recognition of RPA-ssDNA complexes. Science 300: $1542-1548$. 


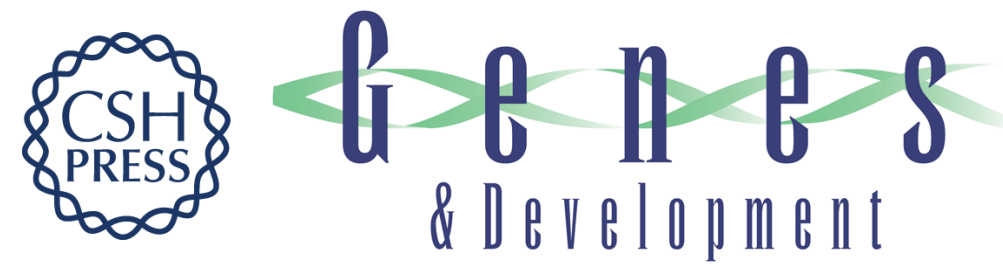

\section{A telomeric repeat sequence adjacent to a DNA double-stranded break produces an anticheckpoint}

Rhett J. Michelson, Saul Rosenstein and Ted Weinert

Genes Dev. 2005, 19:

Access the most recent version at doi:10.1101/gad.1293805

References This article cites 53 articles, 25 of which can be accessed free at: http://genesdev.cshlp.org/content/19/21/2546.full.html\#ref-list-1

License

Email Alerting

Receive free email alerts when new articles cite this article - sign up in the box at the top Service right corner of the article or click here.

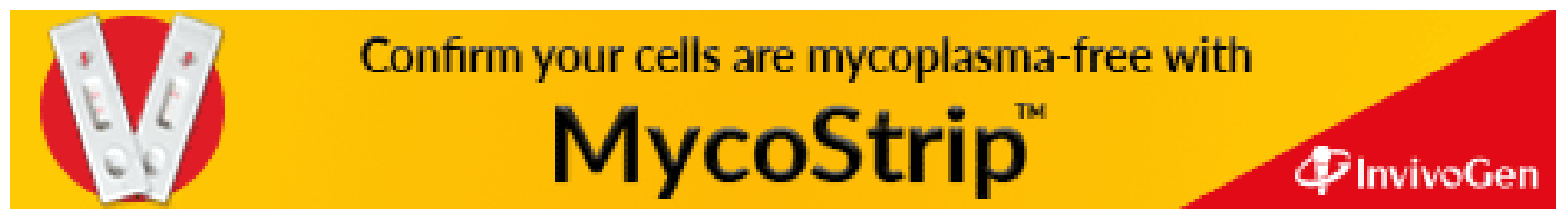

